\title{
Características físico-químicas e sensoriais de aves e ovos
}

Aurora da Silva Melo ${ }^{1}$, Raimunda Thyciana Vasconcelos Fernandes ${ }^{*}$, Vanessa Raquel de Morais Oliveira ${ }^{1}$, João Paulo Araújo Fernandes de Queiroz ${ }^{2}$, Francisca Kelia Duarte Dias $^{3}$, Rosângela Fernandes de Souza ${ }^{4}$, Jéssica Berly Moreira Marinho ${ }^{4}$, Ayala Oliveira do Vale Souza ${ }^{5}$, Claudionor Antonio dos Santos Filho ${ }^{5}$

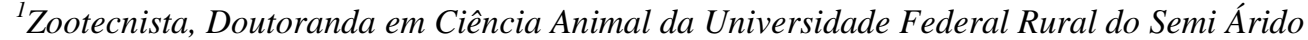 \\ ${ }^{2}$ Médico Veterinário, Doutorando em Ciência Animal da Universidade Federal Rural do Semi Árido \\ ${ }^{3}$ Bióloga, Docente do Instituto Federal do Rio Grande do Norte \\ ${ }^{4}$ Zootecnistas, Mestrandas em Ciência Animal da Universidade Federal Rural do Semi Árido \\ ${ }^{5}$ Graduandos em Zootecnia, Iniciação Científica, Universidade Federal Rural do Semi Árido \\ *Autor para correspondência, E-mail: fernandesrtv@hotmail.com
}

\begin{abstract}
RESUMO. O setor de avicultura pode ser considerado um dos mais desenvolvidos e tecnificados da agropecuária mundial. Os avanços do melhoramento genético aliado ao desenvolvimento da nutrição, sanidade e técnicas de manejo, resultaram na avicultura atual, de alta eficiência e organização com a finalidade de produzir proteína animal de alto valor biológico para o consumo humano a baixo custo. $\mathrm{O}$ ovo comercial é um produto de uma eficiente transformação biológica feita pela galinha de postura e é um dos alimentos mais completos que existe, sendo composto de proteínas, lipídios, vitaminas e minerais. A composição do ovo depende de vários fatores. Cabe ressaltar que a idade da ave influi apenas no tamanho do ovo e na qualidade da casca, mas não em sua composição. A dieta influencia a composição proteica, de ácidos graxos e o conteúdo de colesterol da gema. Por sua vez, quando falamos em carne de aves vem logo em mente a carne branca, com alta umidade e proteína obtida de frangos criados em sistemas convencionais de criação, ou seja, alta densidade e rápido crescimento. Porém, carne de aves é toda e qualquer carne advinda da criação de aves domésticas, e, portanto as características da carne dependem inicialmente da espécie e outros demais fatores, tanto intrínseco como extrínseco da produção, manipuláveis ou não, a fim de atingir padrões de qualidade quanto às características sensoriais, químicas e físicas. Para que a qualidade dos produtos avícolas seja mantida, todos os elos da cadeia, desde o incubatório de ovos às grandes redes de supermercados, devem permanecer unidos para que o consumidor tenha à sua mesa ovos e carnes com características sensoriais desejáveis e livres de resíduos e contaminantes. Desta forma, apresentamos uma revisão sobre as características físico-químicas e sensoriais de aves e ovos.
\end{abstract}

Palavras chave: Capacidade de retenção de água, coloração, índice de gema, pH, Unidade Haugh.

\section{Physicochemical and sensory characteristics of poultry and eggs}

\begin{abstract}
The poultry sector can be considered one of the most developed and technified of world agriculture. Advances in genetic improvement together with the development of nutrition, health and management techniques, resulted in the current poultry farming, high efficiency and organization in order to produce animal protein of high biological value for human consumption at low cost. Commercial egg is a product of an efficient biological transformation made by laying hen and is one of the most complete foods that exists is composed of proteins, lipids, vitamins and minerals. The egg composition depends on several factors. It notes that the bird's age affects only the egg size and shell quality, but not in its composition. The protein composition of the diet influences, fatty acids and cholesterol content of the yolk. In turn, when it comes to poultry coming soon in mind the white meat, with high humidity and protein obtained from chickens raised in conventional farming systems; so, high density and rapid growth. However, poultry meat is any arising meat from poultry, and therefore the characteristics
\end{abstract}


of the meat initially depend other species and other factors, both intrinsic and extrinsic production, manipulated or not in order to reach standards quality as the sensory, chemical and physical characteristics. So that the quality of poultry products is maintained, all links in the chain, from the hatchery eggs to the large supermarket chains, must remain united so that the consumer has at his table eggs and meat with desirable sensory characteristics and free of waste and contaminants. Thus, we present a review on the physicochemical and sensory characteristics of poultry and eggs.

Keywords: Coloring, Haugh Unit, $\mathrm{pH}$, water retention capacity, yolk index.

\section{Introdução}

O setor de avicultura pode ser considerado um dos mais desenvolvidos e tecnificados da agropecuária mundial. Os avanços do melhoramento genético aliado ao desenvolvimento da nutrição, sanidade e técnicas de manejo, resultaram na avicultura atual, de alta eficiência e organização com a finalidade de produzir proteína animal de alto valor biológico para o consumo humano a baixo custo.

O setor avícola parece ter encontrado novamente um bom caminho no ano de 2013, após uma grande crise enfrentada por esse setor em 2012. Curiosamente, cada cadeia produtiva adotou uma estratégia diferente, dentro do momento de demanda de cada produto. Em carne de frango, por exemplo, o inevitável repasse de custos - mesmo que tardio - elevou preços e impactou diretamente (e positivamente) na receita das exportações. A oferta interna seguiu as tendências da demanda em um comportamento bastante ajustado. Embora produzindo menos, tivemos melhor rentabilidade.

Enquanto isto, o setor de ovos encontrou em 2013 um momento bastante favorável para avançar. O mercado interno aquecido refletiu no aumento da produção. Nos embarques, entretanto, problemas burocráticos em Angola (principal mercado) impactaram na redução de volume e receita. Outros setores como perus, patos, pintos e ovos férteis também apresentaram retrações, situação diferente da genética avícola, com ótimo desempenho em receita de exportações (FAPRI, 2015).

É nesse cenário que se espera anos melhores pela frente. O setor avícola deverá focar na inovação das ações e avançar com solidez, tanto no mercado interno, quanto nas exportações. Desta forma, apresentamos uma revisão sobre as características físicoquímicas e sensoriais de aves e ovos.

\section{Revisão de Literatura}

\section{Características físico-químicas e sensoriais} de ovos

O ovo comercial é um produto de uma eficiente transformação biológica feita pela galinha de postura. Estas aves transformam recursos alimentares de menor valor biológico em um produto com alta qualidade nutricional para o consumo humano. A transformação depende de fatores biológicos relacionados à fisiologia da ave e é influenciada pelo aporte nutricional e prática de manejo e ambiente adequados para a sua criação (Bertechini, 2006, Benites et al., 2005).

O ovo é um dos alimentos mais completos que existe, sendo composto de proteínas, lipídios, vitaminas e minerais. Cada um desses componentes pode ser alterado através da manipulação na composição da dieta.

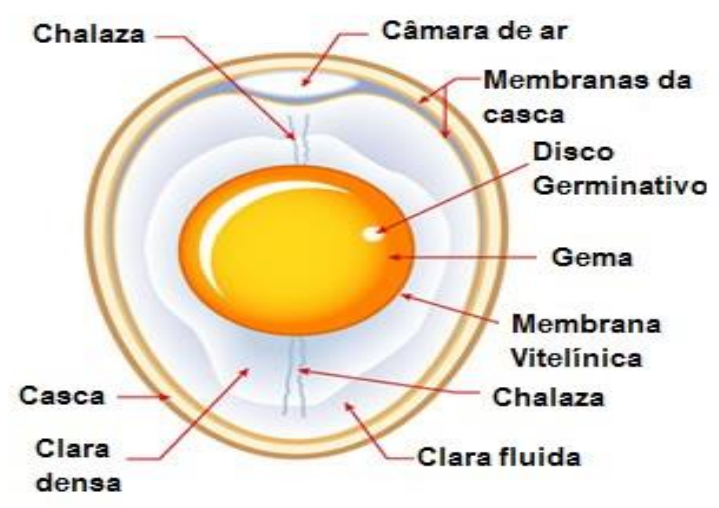

Figura 1. Estrutura do ovo. Fonte: http://www.docampoamesa.com 
A denominação genérica de ovo será empregada apenas para identificar os ovos de galinhas. Ovos de outras aves são designados indicando-se apenas a espécie da qual procedem. As quatro partes principais do ovo são a casca, a membrana da casca, a gema e o albúmen. A casca representa $10 \%$ do peso do ovo, enquanto a gema $30 \%$, e o albúmen $60 \%$. O peso da membrana da casca é desprezível (Fig.1).
A composição do ovo depende de vários fatores. Cabe ressaltar que a idade da ave influi apenas no tamanho do ovo e na qualidade da casca, mas não em sua composição. A dieta influencia a composição protéica, de ácidos graxos e o conteúdo de colesterol da gema. Dados referentes à composição centesimal do ovo de diversas espécies de aves podem ser observados na tabela 1 .

\section{Composição e valor nutritivo}

Tabela 1. Composição centesimal de ovos produzidos por diferentes espécies de aves.

\begin{tabular}{lccccc}
\hline Componentes & Perua & Galinha & Gansa & Pata & Codorna \\
\hline Tamanho & 79 & 50 & 144 & 70 & 9 \\
Valor calórico (kcal/kg) & 168 & 155 & 185 & 185 & 160 \\
Umidade (\%) & 72,50 & 74,57 & 70,43 & 70,83 & 74,35 \\
Gorduras (\%) & 13,68 & 12,14 & 13,85 & 12,81 & 13,05 \\
Proteínas (\%) & 11,88 & 11,15 & 13,27 & 13,77 & 11,09 \\
Carboidratos (\%) & 1,15 & 1,20 & 1,35 & 1,45 & 0,41 \\
Fibras (\%) & 0 & 0 & 0 & 0 & 0 \\
Minerais (\%) & 0,79 & 0,94 & 1,08 & 1,14 & 1,10 \\
\hline
\end{tabular}

Fonte: Adaptado de Souza-Soares \& Siewerdt (2005).

\section{Análises químicas do ovo}

As análises da composição química rotineira realizada no ovo são: umidade (determinado pela perda de peso das amostras, até obtenção de peso constante, em estufa regulada a $105^{\circ} \mathrm{C}$ ) proteína bruta (por digestão, destilação e titulação pelo método Kjeldahl de determinação do nitrogênio, onde o resultado encontrado é multiplicado pelo fator 6,25 para obtenção da proteína bruta) extrato etéreo (por extração com o uso de solventes de acordo com o método Soxhlet), fibra (por lavagem com solventes de acordo com metodologia desenvolvida por (Van Soest et al., 1991) e matéria mineral por incineração em mufla a $600^{\circ} \mathrm{C}$ por 4 horas, todos seguindo metodologias descritas por AOAC (2005), Silva \& Queiroz (2002) e Instituto Adolfo Lutz, dentre outros.

Outras análises mais sofisticadas podem ser feitas, como por exemplo, análise de aminoácidos (feita em cromatografia líquida de alta eficiência e espectroscopia infravermelho próximo), vitaminas lipossolúveis (feita em cromatografia líquida de alta eficiência e espectroscopia infravermelho próximo), macro, micro minerais e elementos traço (feitas por espectrometria de absorção atômica).

\section{Análises físicas do ovo}

\section{Ovoscopia}

Análise realizada através de equipamento ovoscópio, onde a condição do ovo é julgada, segurando-o à frente de um foco de luz, em uma sala escura. A luz do ovoscópio revela a condição da casca, o tamanho da câmara de ar, a nitidez, a cor e a modalidade da gema, valendo-se de voltas rápidas do ovo na esteira. O estado do albúmen pode ser também determinado pela posição e pela liberdade de movimentos da gema. Anormalidades, tais como manchas de sangue, desenvolvimento embrionário e deterioração também são evidentes.

\section{Unidade Haugh}

Unidade "Haugh" é uma expressão matemática que correlaciona o peso do ovo com a altura da clara espessa. De modo geral, quanto maior o valor da unidade "Haugh", melhor a qualidade do ovo. Pode ser determinado pela equação abaixo: 


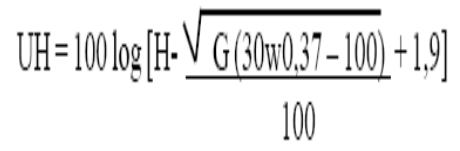

Onde:

$\mathrm{H}$ : altura de albúmen

G: constante de Haugh - 32

$\mathrm{W}$ : peso do ovo $(\mathrm{g})$

\section{Índice de gema}

Índice que relaciona altura da gema e seu diâmetro para complementar a Unidade Haugh. É determinado através da equação:

\section{$I G=A G / D G$}

Onde:

AG: altura de gema

DG: diâmetro de gema

\section{Gravidade específica}

Método indireto ou não-destrutivo para avaliar a qualidade da casca do ovo. Baseiase no princípio de Arquimedes, onde se eleva a densidade da água através da adição de cloreto de sódio. A verificação da densidade é feita através de densímetro. $\mathrm{O}$ ovo é então testado em baldes com água e cloreto de sódio em concentrações crescentes (consequentemente, a densidade também é crescente), o balde em que o ovo flutuará corresponderá à densidade do mesmo. Quanto mais alta a densidade da água com cloreto de sódio, melhor será a qualidade do ovo.

\section{Cor da gema}

Realizada através de leques colorimétricos (Figura 2), que indicará a intensidade do amarelo, variando de pouco amarelo a muito intenso ou laranja, ou através de cromatógrafos ou espectrofotômetros, que através do sistema CIELab indicará a luminosidade, o teor de amarelo e o teor de vermelho. Os usos dos leques colorimétricos são pouco preciso, uma vez que diferentes pessoas podem identificar colorações discrepantes em uma mesma amostra.

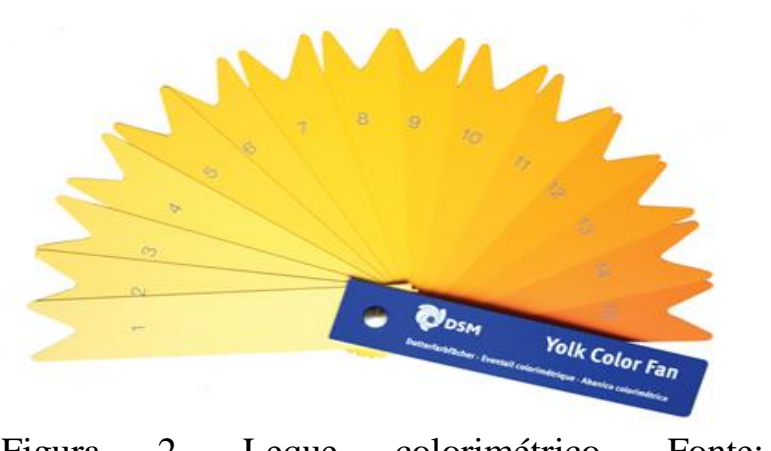

Figura 2. Leque colorimétrico. Fonte: http://www.ahoradoovo.com.br

\section{Análises sensoriais do ovo}

A análise sensorial mais utilizada é o teste de aceitação global, onde julgadores treinados ou não recebem amostras do ovo e terá que indicar a sua impressão geral (cor, odor, sabor, textura), conforme escala hedônica estruturada em 9 pontos variando de desgostei extremamente à gostei extremamente (Dutcosky, 2011).

Posteriormente o julgador também indicará a sua intenção de compra, estruturada em uma escala hedônica de 5 pontos variando de certamente eu compraria à certamente não compraria.

Ao final, será calculado o índice de aceitabilidade conforme abaixo:

$$
I A(\%)=\left[\frac{\text { nota média obtida para o produto }}{\text { nota máxima dada a produto }}\right] \times 100
$$

Quanto mais próximo de $100 \%$ for o índice, melhor a sua aceitabilidade. Índices acima de $70 \%$ são considerados aceitáveis.

\section{Características físicas químicas e sensoriais da carne de aves}

Quando falamos em carne de aves vem logo em mente a carne branca, com alta umidade e proteína obtida de frangos criados em sistemas convencionais de criação, ou seja, alta densidade e rápido crescimento. Porém, carne de aves é toda e qualquer carne advinda da criação de aves domésticas e, portanto, as características da carne dependem inicialmente da espécie e outros demais fatores, tanto intrínseco como extrínseco da produção, manipuláveis ou não, a fim de atingir padrões de qualidade quanto 
às características sensoriais (textura, suculência, sabor, odor e aparência), químicas (porcentagem de proteína, gordura, fibras totais, cinza, perfil de ácidos graxos e de aminoácidos e conteúdo de minerais e vitaminas) e características físicas $(\mathrm{pH}$, capacidade de retenção de água, força de cisalhamento, cor, perda de peso por cocção).

No entanto, outras variáveis poderiam se analisadas e mostradas sobre a composição da carne de aves.

\section{Características Físicas da carne de aves}

$p H$

$\mathrm{O}$ declínio do $\mathrm{pH}$ altera a composição celular e extracelular das fibras musculares, resultando em redução de grupos reativos disponíveis para reter água nas proteínas, resultando em redução de grupos reativos disponíveis para reter água nas proteínas e por isso está relacionado com a maciez retenção de água da carne. Capacidade de retenção de água: relacionada com textura e maciez da carne e está intimamente relacionada ao pH (Offer \& Knight, 1988).

\section{Perda de peso por cocção}

É relacionada ao conteúdo de umidade e rendimento da carne. Para a perda de peso por cocção as amostras são descongeladas em temperatura ambiente, pesadas $\mathrm{e}$ embaladas individualmente em papel alumínio, submetidas à cocção em chapa (grill) pré-aquecida a $170^{\circ} \mathrm{C}$, até atingir $80^{\circ} \mathrm{C}$ $\left(70-80^{\circ} \mathrm{C}\right)$ no centro geométrico (verificada por termômetro de mercúrio). As amostras são então, secas em papel absorvente e esfriadas a temperatura ambiente e pesadas.

\section{Cor}

É a absorção seletiva da luz pela mioglobina e por outros importantes componentes, como as fibras musculares e suas proteínas, sendo também influenciado pela quantidade de líquido livre presente na carne (Olivo, 2006). O componente que confere cor a carne é a mioglobina, quanto maior o tamanho, atividade muscular do animal, maior o teor de mioglobina e mais escura é a carne (Venturini et al., 2007, Mancini \& Hunt, 2005).

\section{Características químicas da carne de aves}

Vários aspectos contribuem para a variação nos parâmetros umidade, proteína, extrato etéreo e cinzas, tais como: raça, grupo genético, sexo, idade e dietas. E dentre esses componentes químicos, o extrato etéreo é o componente que mais mostra variação, enquanto o valor de proteína e aminoácidos o de menor variação, apresentando sempre proteína de alto valor biológico por conter em sua composição aminoácidos essenciais (Olivo, 2006).

\section{Características sensoriais da carne de aves}

As características sensoriais são as mais influenciadas por todos os fatores ao levar em consideração que o sabor e odor da carne são adquiridos no produto final e possuir muitos fatores que afetem essa característica. A carne de frango é, no entanto a mais apreciada pelo apelo monetário e pela maciez e fácil deglutição do produto (Komiyama et al., 2010).

\section{Fatores que afetam a qualidade da carne}

\section{Intrínsecos}

A espécie animal ao qual está se tratando possui diferenças quanto às características da carne, desde a coloração quanto à maciez, devido à diferença entre número e conformação de fibras musculares, até aos hábitos comportamentais obtidos durante a evolução. Entre mesma espécie diferenças entre linhagens, sexo, idade e até o corte podem afetar as características físicas, químicas e sensoriais da carne de frangos, por exemplo, (Santos et al., 2005).

\section{Linhagem}

As linhagens são resultado de seleção genética para características desejadas na produção que também é responsável por ditar o crescimento e características das fibras musculares e deposição de gordura das aves. Linhagens comerciais de frangos apresentam carne de coloração pálida enquanto linhagens "caipiras" apresentam coloração mais 
avermelhadas; além disso, a primeira é caracterizada por um maior $\mathrm{pH}$ e menor textura do que a segunda (Santos et al., 2005). As aves selecionadas para alta taxa de crescimento tendem a possuir fibras musculares maiores e em maior número do que aves não selecionadas, entretanto as proporções de tipos de fibras musculares não se alteram entre estes animais, afetando a textura da carne. Outra característica afetada pela linhagem é a deposição de gordura diferenciada em animais de crescimento lento capaz de afetar a composição química da carne, maciez e sabor (Remignon et al., 1995).

\section{Idade}

Quanto mais tardio o abate menor a porcentagem de umidade e proteína, enquanto que a proporção de lipídios é aumentada. Esse aumento de gordura pode favorecer a qualidade da carne por diminuir a velocidade de resfriamento da carcaça, evitando a desidratação, o escurecimento e mantendo a maciez da carne (Faria et al., 2009). Também com o avançar da idade há aumento no número de ligações cruzadas intra e entre as moléculas de tropocolágeno do colágeno, conferindo maior estabilidade a esta molécula, mas em contra partida aumenta a insolubilidade do colágeno, como consequência, com o avançar da idade do animal a carne se torna mais dura (Listrat et al., 2000).

\section{Sexo}

Devido ao dimorfismo sexual, o desenvolvimento dos tecidos é diferente entre os gêneros. O macho apresenta uma taxa anabólica de deposição de tecido muscular superior a das fêmeas e a deposição de tecido adiposo é mais tardia. Ao abate, em idades semelhantes às fêmeas irão apresentar maior quantidade de tecido adiposo em relação aos machos (Faria et al., 2009).

\section{Sistema de criação}

O sistema de criação determinará o quanto de liberdade o animal terá, dessa forma o sistema intensivo é o que permite menor movimentação do animal, variando de acordo com a densidade de criação e o sistema extensivo maior movimentação. A quantidade de atividade física realizada pelo animal irá proporcionará maior gasto de energia para mantença e, por isso, menor peso corporal e menor porcentagem de gordura abdominal (Madeira et al., 2010). Além disso, o sistema de criação também determinará o tipo de alimentação ofertada aos animais e assim afeta diretamente as características da carne.

\section{Extrínsecos}

Nos processos de engorda e abate existem alguns fatores que podem afetar as características da carne entre eles a alimentação, o manejo e os períodos pré e pós abate.

\section{Alimentação}

A gordura na carcaça é um dos fatores que mais afetam os parâmetros de qualidade da carne, desde a composição à maciez da carne. Além disso, a síntese no organismo é mais dispendiosa que a de tecido muscular, precisando dessa forma controlar essa característica. Na nutrição, a porcentagem de gordura pode ser manipulada a partir dos níveis dietéticos de energia, inclusão de aditivos e níveis de fibra nas dietas. A suplementação de cromo em dietas de frangos, por exemplo, possui relação quadrática com a porcentagem de extrato etéreo da carne de peito de frango (Souza et al., 2010). Outros fatores manipuláveis são o perfil de ácidos graxos e aminoácidos na carcaça, capazes de afetar não só a composição química como o pH, maciez e tempo de prateleira.

\section{Período pré-abate}

O momento pré-abate é decisivo para a qualidade da carne, pois é nesse momento que ocorrem as principais alterações no músculo, para posterior transformação em carne. Animais estressados no momento pré abate liberam catecolaminas e glicocorticóides capazes de elevar o metabolismo dos animais acelerando a transformação do músculo em carne, afetando principalmente o $\mathrm{pH}$ final que 
atinge precocemente valores abaixo de 6 enquanto a temperatura da carcaça ainda está alta, levando a desnaturação protéica e ao aparecimento de carne PSE (pálida, mole e exsudativa). $\mathrm{O}$ fenômeno PSE em frangos pode ser detectado pela combinação dos valores de $\mathrm{pH}$ (abaixo de 5,8) e cor (valor $\mathrm{L}^{*}$ acima de 52,0) aferidos em 24 horas após o abate (Lara et al., 2002).

Outro fator capaz de afetar o $\mathrm{pH}$ final da carne e assim afetar a qualidade da carne é o jejum pré abate. Em jejum prolongado (acima de 8 horas) podem ocasionar o esgotamento do glicogênio muscular e a baixa produção de ácido láctico, deixando o $\mathrm{pH}$ elevado caracterizando carne DFD (dura, escura e seca), $\mathrm{pH}$ final acima de 6,2 e $\mathrm{L}^{*}$ $<44$.

\section{Pós abate}

O metabolismo muscular post mortem resulta em mudanças estruturais das fibras. Quando as reservas de ATP se esgotam, ocorre a ligação irreversível das moléculas de actina e miosina, caracterizando o rigor mortis, ou a rigidez cadavérica. Ocorre a perda da elasticidade e o aumento da tensão muscular, e a dureza da carne atinge o seu valor máximo. A principal consequência do estado de rigidez cadavérica é o encurtamento máximo dos sarcômeros. O comprimento do sarcômero é correlacionado positivamente com a maciez da carne $(\mathrm{r}=0,80)$. Um dos fatores que mais afetam o tamanho final alcançado pelo sarcômero é a temperatura em que a carcaça é submetida durante $o$ período que antecede o aparecimento da rigidez cadavérica. Conforme a temperatura ambiente vai baixando ou esfriando, aumenta o encurtamento do sarcômero, diminuindo a maciez da carne. $\mathrm{O}$ encurtamento dos sarcômeros pelo frio pode ser minimizado quando as carcaças apresentam um bom acabamento de gordura (Listrat et al., 2000).

\section{Considerações finais}

A avicultura de corte e postura segue uma tendência mundial de preocupar-se em oferecer produtos de qualidade aos seus consumidores. No entanto, para que esta qualidade seja mantida todos os elos da cadeia, desde o incubatório de ovos às grandes redes de supermercados, devem permanecer unidos para que o consumidor tenha à sua mesa ovos e carnes com características sensoriais desejáveis e livres de resíduos e contaminantes.

\section{Referências Bibliográficas}

AOAC. 2005. - Association Official Analytical Chemist (2005). Official Methods of Analysis (18th ed.) edn. AOAC, Gaitherburg, Maryland, USA.

Benites, C., Furtado, P., Seibel, N., SouzaSoares, L. \& Siewerdt, F. 2005. Características e aspectos nutricionais dos ovos. In: Souza-Soares, L. (ed.) Aves e ovos. Ed. da Universidade UFPEL, Pelotas.

Bertechini, A. G. 2006. Nutrição de monogástricos. Universidade Federal de Lavras, Lavras.

Dutcosky, S. 2011. Análise sensorial de alimentos. 3th ed. Editora Champagnat, Curitiba, Paraná.

FAPRI. 2015. Food and Agricultural Policy Research Institute. In: Database, W. A. O. (ed.) Food and Agricultural Policy Research Institute. Iowa State University and University of Missouri-Columbia Ames, IA, USA.

Faria, P. B., Bressan, M. C., Souza, X., Rodrigues, E., Cardoso, G. \& Gama, L. 2009. Composição proximal e qualidade da carne de frangos das linhagens Paraíso Pedrês e Pescoço Pelado. Revista Brasileira de Zootecnia, 38, 2455-2464.

Komiyama, C. M., Mendes, A. A., Sanfelice, C., Cañizares, M. C., Roça, R. O., Takahashi, S. E., Rodrigues, L., Cañizares, G. I. L., Paz, I. \& Cardoso, K. F. d. G. 2010. Qualidade físico-química e sensorial da carne de peito de matrizes pesadas de descarte. Ciência Rural, 40, 1623-1629.

Lara, J., Ninov, K., Bonassi, C., Ledur, M., Nepomuceno, A. \& Shimokomaki, M. 2002. Estresse térmico e incidência de carne PSE em frangos. Revista Brasileira de Ciência Avícola, 4, 15.

Listrat, A., Lethias, C., Hocquette, J. F., Renand, G., Menissier, F., Geay, Y. \& Picard, B. 2000. 
Age-related changes and location of types I, III, XII and XIV collagen during development of skeletal muscles from genetically different animals. Histochemical Journal, 32, 349-356.

Madeira, L. A., Sartori, J. R., Araujo, P. C., Pizzolante, C. C., Saldanha, E. \& Pezzato, A. C. 2010. Avaliação do desempenho e do rendimento de carcaça de quatro linhagens de frangos de corte em dois sistemas de criação. Revista Brasileira de Zootecnia, 39, 22142221.

Mancini, R. A. \& Hunt, M. C. 2005. Current research in meat color. Meat Science, 71, 100121.

Offer, G. \& Knight, P. 1988. The structural basis of water-holding in meat. Part 1: general principles and water uptake in meat processing. In: R., L. (ed.) Developments in meat science. Elsevier Applied Science, London, New York.

Olivo, R. 2006. Estrutura, composição e funcionalidade do tecido muscular. In: Olivo, R. (ed.) $O$ mundo do frango. Criciúma.

Remignon, H., Gardahaut, M., Marche, G. \& Ricard, F. 1995. Selection for rapid growth increases the number and the size of muscle fibres without changing their typing in chickens. Journal of Muscle Research \& Cell Motility, 16, 95-102.

Santos, A. L., Sakomura, N. K., Freitas, E. R., Maria, C., Fortes, L. S., Carrilho, E. N. V. M. \& Fernandes, J. B. K. 2005. Estudo do crescimento, desempenho, rendimento de carcaça e qualidade de carne de três linhagens de frango de corte. Revista Brasileira de Zootecnia, 34, 1589-1598.

Silva, D. J. \& Queiroz, A. C. 2002. Análise de alimentos: métodos químicos e biológicos, 3 edn. Universdiade Federal de Viçosa, Viçosa, Minas Gerais, Brasil.

Souza, L., Murakami, A. E., Fernandes, J. I. M., Guerra, R. \& Martins, E. N. 2010. Influência do cromo no desempenho, na qualidade da carne e no teor de lipídeos no plasma sanguíneo de frangos de corte. Revista Brasileira de Zootecnia, 39, 808-814.

Van Soest, P. J., Robertson, J. B. \& Lewis, B. A. 1991. Methods for dietary fiber, neutral detergent fiber, and nonstarch polysaccharides in relation to animal nutrition. Journal of Dairy Science, 74, 3583-3597.

Venturini, K. S., Sarcinelli, M. F. \& Silva, L. 2007. Características da carne de frango. Universidade Federal do Espírito Santo, Vitória.

\section{Recebido em Agosto17, 2015}

Aceito em Setembro 22, 2015

License information: This is an open-access article distributed under the terms of the Creative Commons Attribution License, which permits unrestricted use, distribution, and reproduction in any medium, provided the original work is properly cited. 